\title{
Biofilm Matrix Formation in Human: Clinical Significance, Diagnostic Techniques, and Therapeutic Drugs
}

\author{
Mehdi Goudarzi (iD) ${ }^{1}$, Masoumeh Navidinia (iD ${ }^{2,}{ }^{,}$, Naghmeh Khadembashi ${ }^{3}$ and Ramin Rasouli ${ }^{4}$ \\ ${ }^{1}$ Department of Microbiology, School of Medicine, Shahid Beheshti University of Medical Sciences, Tehran, Iran \\ ${ }^{2}$ Department of Medical Laboratory Sciences, School of Allied Medical Sciences, Shahid Beheshti University of Medical Sciences, Tehran, Iran \\ ${ }^{3}$ English Language Department, School of Allied Medical Sciences, Shahid Beheshti University of Medical Sciences, Tehran, Iran \\ ${ }^{4}$ Department of Microbial Biotechnology, Faculty of Basic Sciences and Advanced Technologies in Biology, University of Science and Culture, Tehran, Iran \\ "Corresponding author: Department of Laboratory Sciences, School of Allied Medical Sciences, Shahid Beheshti University of Medical Sciences, Tehran, Iran. Tel/Fax: \\ +98-2126850560, Email: dr.navidinia@sbmu.ac.ir
}

Received 2020 November 11; Revised 2021 July 06; Accepted 2021 August 22.

\begin{abstract}
Context: Some recent reports have indicated that almost $80 \%$ of clinical infections in humans have biofilm origin and impose additional healthcare costs. This study was an updated review of extracellular polymeric substance matrix (Biofilm) formation in humans and elaborated on its clinical significance, diagnosis, and therapeutic approaches.

Evidence Acquisition: This narrative study reviewed the most recent information on the significance of microbial biofilm formation in clinical settings, common biofilm-producing bacterial species, its diagnosis, antibiotic drug resistance, and new approaches to the treatment of infections associated with biofilm formation.

Results: Evidence indicated a permanent increase in the frequency of microbial biofilm in the central venous catheter, mechanical heart valve, and urinary catheter, as well as persistent infections. However, antimicrobial resistance induced by biofilms formation and the antimicrobial treatment of biofilms were problematic. Moreover, several assays and lab devices were described to evaluate biofilm formation. Furthermore, new attitudes towards anti-biofilm treatments were introduced in this paper.

Conclusions: The number of different mechanisms were in accordance with the recent knowledge on how biofilms play a critical role in the disease pathogenesis. Biofilm strikes the treatment and surveillance of patients bearing infectious diseases under different conditions. The use of new methods in anti-biofilm treatments is effective for the recovery of infected patients.
\end{abstract}

Keywords: Biofilm Matrix, Clinical Significance, Diagnostic Techniques, Therapeutic Drugs

\section{Context}

Biofilms mainly comprise microbial cells and exopolysaccharides (EPS) (1) and connect to abiotic surfaces. The adhesion step is essential for the bacteria arranged in their environmentally favorable conditions (2). Bacterial growth is characterized by planktonic or sessile aggregates. Sessile aggregates are commonly referred to as a biofilm and contain multiple bacteria forming a consortium (3). Figure 1 shows the stages involved in the formation and life cycle of a biofilm. A biofilm acts as a protection factor for the bacteria against antimicrobial and host immune system attacks and favors infection chronicity. Quorum sensing systems (QS) is a cellular recognition mechanism which regulate biofilm formation. Since biofilm formation can pose remarkable problems in the Health settingby, stimulating further resistance to the treatment with antibiotics and biocides, it even decreases host immune responses (4).
The pathophysiology of biofilms is involved in the bacteria colonization process and disseminative stages. In the disseminative stages and colonization processes, the bacteria emerge in a planktonic form; however, the biofilm formation steps are determined by cellular accumulations in a distinguished form and physiology (6).

Microbial biofilms are normally out of access to antibiotics and the human immune system. Biofilmproducing bacteria present resistant phenotypes due to some changes e.g., nutritional status or cell density, temperature, osmolarity, and $\mathrm{pH})(7)$.

According to the statistics, about $80 \%$ of clinical infections in human are associated with biofilms. Due to the effect of microbial biofilms on the care and treatment strategies, millions of dollars have been spent in ambiguity for a long term. A biofilm is quickly produced on stainless steel and titanium orthopedic bolts and encompasses powerful adhesion forces to stick to foreign bodies 


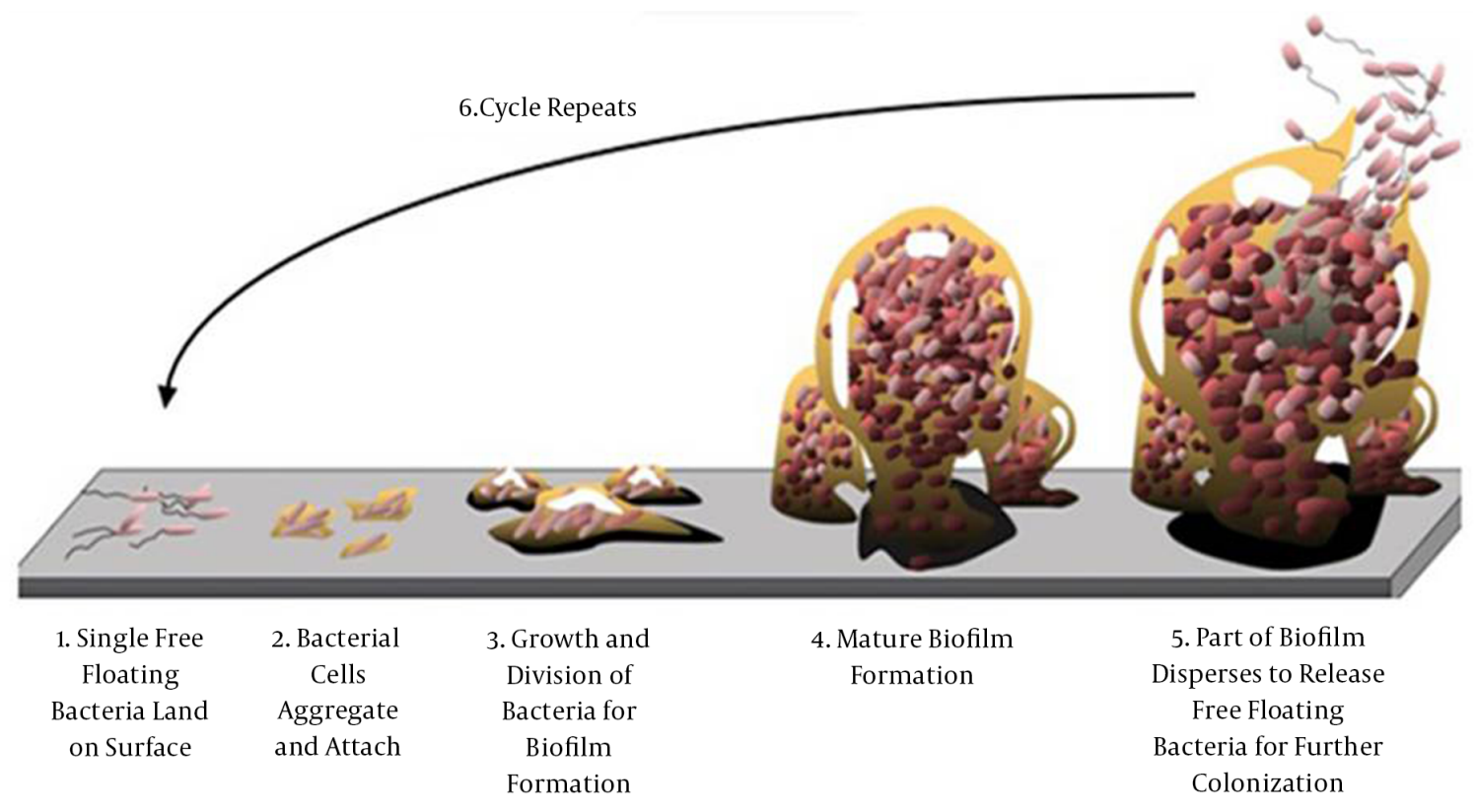

Figure 1. Adhesion step and sessile aggregation of a biofilm (5)

by some bacteria such as Staphylococcus aureus, S. epidermidis, and Pseudomonas aeruginosa $(8,9)$. Some diseases induced by biofilm formation are pneumonia, skin infections, food poisoning, endocarditis, osteomyelitis, soft tissue infections, septic arthritis, cystic fibrosis, periodontitis, and UTI, which are mainly caused by indwell medical devices and life-threatening invasions (10-19). In some microorganisms, cell-cell signaling during sporulation exhibits different cellular forms containing distinguished cell types, thereby enhancing survival via the labor division (20). There are some medically-significant fungi producing biofilms such as Candida, Pneumocystis, Aspergillus, Trichosporon, Coccidioides, and Cryptococcus (21). Unfortunately, recent reports have described a worldwide increase in the prevalence of these organisms as well as high mortality and morbidity rates in healthcare settings as such, they have been a major concern worldwide. To make appropriate policies, national information is required to revise the essential drugs' list for treatment and evaluate the effects of intervention strategies (22). Biofilm formation as a virulence determinant may result in the development of multi-drug resistance. For example, Acinetobacter is the leading cause of hospital-acquired infections worldwide. In this regard, there are some reasons as follows: (1) tendency to create someinfections in critically-ill patients; (2) predilection to develop resistance to multiple antibiotics; and (3) survivability for a long term on equipment and hospital surfaces, and several outbreaks attributed to common source contamination. Moreover, the MDR, XDR, and PDR (representing multi-, extensive- and pan-drug resistant) strains of A. baumannii have been reported worldwide (23-25).

There is an urgent need to study factors in charge of spreading antibiotic resistance and gene transfer. Some genes associated with biofilm formation result in treatment failure among wound infections due to the involvement of some highly resistant bacteria (26). Wound infection in burned patients should be demonstrated as a potential risk due to antibiotic-resistant bacteria such as $P$. aeruginosa, Acinetobacter, and Klebsiella (4).

Moreover, in burn centers, the rapid acquisition of MDR result in high morbidity and mortality rates. After exposure to various antibiotics and cross-resistance may emerge some resistant strains such as MDR, XDR, and PDR. Consequently, given the rapid emergence of hospital antibiotic-resistant pathogens, the periodic assessment of antibiogram sensitivity and bacterial colonization patterns in burn wards seems crucial (27).

During the last decade, the significance of biofilms in clinical settings was documented. Infections induced by biofilms are observed in all parts of human body. Now, biofilm-forming bacteria seem to be associated with chronic infections (28).

Accordingly, this study described an updated review of biofilm matrix formation in human regarding its clinical significance, diagnosis techniques, and therapeutic drugs. 


\section{Evidence Acquisition}

In this narrative review, a comprehensive review of the relevant literature further revealed structural and functional variations. Moreover, it was noticed that biofilms play a role in disease and host-pathogen interactions. The present study describes the most recent information on the significance of microbial biofilm formation in clinical settings, common biofilm producing bacteria, antibiotic drug resistance, its diagnostic methods, and new approaches to the treatment of infection induced by biofilm formation.

\section{Results}

\subsection{Significance of Biofilms in Clinical Settings}

According to a comprehensive review of the literature, about $99.9 \%$ of bacteria produce biofilms at biological and inanimate levels. Biofilm producing has been reported in a large number of gram positive (S. epidermidis, S. aureus, Actinomyces israelii) and gram negative (E. coli, Klebsiellapneumonia, Enterobacter cloacae, Pseudomonas aeruginosa, Burkholderia cepacia, Haemophilus influenza, and A. baumannii) bacteria (29-32).

Some infections are associated with residing prosthesis and implantable devices. Tables 1 and 2 present the list of human infections induced by indwelling devices and those involving biofilms $(33,34)$. Table 3 also presents human infections induced by indwelling devices, and Table 4 shows human infections caused by biofilm-producing bacteria. A list of some medical devices by which biofilms can develop is presented in Table 5. Some medical devices, by which biofilms can develop, are as follows: (1) prosthetic joint; (2) endotracheal tubes; (3) tympanostomy tubes; (4) peritoneal dialysis catheters; (5) voice prostheses; (6) pacemakers; (7) urinary catheters; (8) contact lenses; (9) mechanical heart valves; (10) central venous catheters; (11) intrauterine devices; and (12) central venous catheter needless connectors (35).

Biofilms associated with central venous catheters (CVC) are used to provide fluid, blood products, nutrition or medications, and access to the dialysis treatment (7, 35). However, the contamination of the external or internal parts of the catheter leads to biofilm formation. After the first week of catheterization, extra luminal biofilm can cause catheter-associated bloodstream infections. Conversely, some evidence from luminal colonization and biofilm formation is obtained after indwelling vascular catheters for more than 30 days. Accordingly, patients requiring the long-term use of devices (e.g., patients with bone marrow transplantation) are at greater risk of developing blood infections $(37,38)$.
Biofilms can stick to the material of mechanical heart valves and heart surrounding tissues, inducing a disease called prosthetic endocarditis. In this regard, some of the main bacteria associated with this disease are Gram negative bacilli, diphtheroids, Candida spp, S. epidermidis, S. aureus, Streptococcus spp., and enterococcus spp. These organisms may appear because of using devices such as CVC or following dental procedures (7).

The nature of causative agents is associated with their origin. Some contamination-arousing organisms (e.g., early endocarditis induced by S. epidermidis) originate at the surgery time. Some organisms (e.g., Streptococcus spp.) emanate after dental work. Because of indwelling a medical device, several organisms may exhibit infections. After residing the mechanical heart valve, there may be some events such as the accumulation of circulating platelets, fibrin attachment to the valve, and tissue damage. Similarly, the bacteria's greater tendency to attach to these locations is documented. Moreover, biofilms reach the tissue around the prosthesis or can stick to the synthetic medical devices. Generally, antimicrobial drugs are administered after the valve replacement and dental procedures to prevent early sticking by killing all bacteria spread into the bloodstream. According to some studies, only a small number of patients can be released from an infection induced by biofilm only by adopting antibiotic treatment (31, 32,37 ).

Catheters are commonly necessary for patients not capable of voiding. A urinary catheter is a hollow, construction rubber or plastic (PVC) silicone, flexible tube in several sizes and types, which gathers urine from the bladder and propels it to a drainage bag. The disruption in emptying the bladder can pose pressure on kidneys. Kidney dysfunction occurs following such pressure, which can be hazardous and causes kidneys' persistent damage. Catheters are often used for a short period of time; however, the elderly and patients with a persistent injury or drastic illness may need catheters for a long time (38). A catheter-induced infection was increased by about 10\% per day of using the catheter. Both the internal and external surfaces of urinary catheters can be readily expanded by biofilms colonization, and this condition cannot be deviated merely via hygiene scale. Hence, clinicians should prescribe catheters only in the case of necessity and forbear catheterization for a prolonged or continuous period (7). The contamination may be aroused by those bacteria colonized in the periurethral region. They can move into the bladder via the mucosal lining that is within the epithelial cells or the urethra region and the catheter. Urine contamination may happen in the catheter drainage bag and induce infections in that patient. IN this regard, the most frequent strategy is the catheter elimination and substitution. Catheter 
Goudarzi M et al.

\begin{tabular}{|c|c|}
\hline Variables & Values \\
\hline General aspect of clinical signs & $\begin{array}{l}\text { (In some cases) low-grade fever, loss of function, dolor, low-grade inflammatory reactions tumor, and rubor; } \\
\text { Implanted medical device and cystic fibrosis (CF) disease as the medical history of biofilm-predisposing } \\
\text { situations; All persistent and lasting ( > 7 days) infections, antibiotic resistance during treatment; Infection } \\
\text { relapse and antibiotic treatment defeat; Documented record / antibiotic defeat background; All systemic } \\
\text { signs and infection symptoms resolve with antibiotic therapy. }\end{array}$ \\
\hline Microbiological diagnostics & $\begin{array}{l}\text { A-Microscopic evidence of tissue/ fluid samples gathered from suspected infection location; Microscopic } \\
\text { evidence disclosing microbial aggregates by the examination of fluid sample or smear; Microscopic evidence } \\
\text { Microscopic evidence disclose microbial co-localized together with inflammatory cells; Microbiological } \\
\text { document confirm with infectious etiology }\end{array}$ \\
\hline $\begin{array}{l}\text { B- Microbial microorganisms indicated by a few } \\
\text { procedures (e.g., positive } \\
\text { culture/non-culture-based (PCR) of tissue or liquid } \\
\text { example) }\end{array}$ & $\begin{array}{l}\text { Microbial pathogens detected by culture (MALDI-TOF); Mucoid settlements or variations of Pseudomonas } \\
\text { aeruginosa small colony in culture-positive examples, indicating anti-infection disobedience; Positive } \\
\text { outcomes detected by a few molecular techniques (e.g., PCR, quantitative PCR, or multiplex PCR for microbes } \\
\text { related to contamination with P. aeruginosa and CF, Staphylococcus aureus related to contamination with } \\
\text { implant); The positive outcome of fluorescence in situ hybridization for well-known pathogens displaying } \\
\text { snuggled microorganisms; Microbial pathogen detected by several non-culture-based techniques such as } \\
\text { next-generation sequencing, pyrosequencing, specific immune reaction to known bacteria such as } P \text {. } \\
\text { aeruginosa antigens in patients with CF (if infections induced by biofilm last for about } 2 \text { weeks.) }\end{array}$ \\
\hline
\end{tabular}

Table 2. Common Anatomic Site of Human and Foreign Bodies for Biofilm Colonization (29)

\begin{tabular}{ll}
\hline Anatomic site A with normal flora & $\begin{array}{l}\text { Anatomic site B without normal } \\
\text { flora }\end{array}$ \\
\hline $\begin{array}{l}\text { Skin; Pharynx; Duodenum; } \\
\text { Urethra; Vagina; Air in operating } \\
\text { room, skin flora }\end{array}$ & $\begin{array}{l}\text { Blood, peritoneum; Bronchi, lungs; } \\
\text { Bile tract, pancreas; Bladder; Uterus; } \\
\text { Neurosurgical shunt, alloplastic } \\
\text { material }\end{array}$ \\
\hline No symptoms & Pathology \\
\hline
\end{tabular}

\begin{tabular}{|c|c|}
\hline Device & Infection \\
\hline Peritoneal dialysis catheters & Exit-sit-infections, peritonitis \\
\hline Hemodialysis catheters & $\begin{array}{l}\text { Access site infections, endocarditis, } \\
\text { bacteremia }\end{array}$ \\
\hline Urinary catheters & Urinary tract infections, bacteremia \\
\hline Intravenous catheters & Access site infections, bacteremia \\
\hline Prosthetic cardiac valves & Prosthetic valve endocarditis, bacteremia \\
\hline CSF shunts and reservoirs & Access site infection, meningitis \\
\hline Cardiac pacemakers & $\begin{array}{l}\text { Lead and generator infections, } \\
\text { endocarditis }\end{array}$ \\
\hline Contact lenses & Conjunctivitis, endophthalmitis \\
\hline Surgical sutures \& staples & Urinary tract infections \\
\hline
\end{tabular}

disruption and displacement can pose further complications; hence, biofilm can sheds planktonic cells or aggregates of cells after indwelling device and provides bacterial spread to other anatomical places in body. It is proved that urease production by some bacteria increases the urinary $\mathrm{pH}$ and promotes crystalline biofilm formation in the urinary catheter. Sometimes, crystalline biofilms appear on the catheter's external surface (e.g., catheter tip and surrounding balloon), causing trauma to the urethral epithelia and bladder. Then, because of stone formation, biofilm debris can cause obstruction in the bladder. Furthermore, the crystalline biofilm can cause catheter lumen obstruction and urine flow obstruction by the catheter (33).
Recurrent UTIs are popular among young, healthy women, even those whose urinary tracts have a normal structure anatomically and physiologically. One of the substantial burdens to the healthcare system is that almost $25 \%$ of women with acute cystitis experience recurrent UTIs. In this regard, some studies have highlighted the significance of detecting the main factors causing recurrent UTIs to expand effective prevention methods and therapies (39). Relapse induced by uropathogenic E. coli (UPEC) is associated with these strains' potentials for biofilm formation. As a result, biofilm formation is the main feature of the UPEC persistence not only in the vaginal reservoir but also in the bladder epithelial cells (39-44).

\subsection{Antibiotic Drug Resistance}

Compared to planktonic cells, biofilm-producing bacteria adopting several mechanisms can be more resistant against antibiotics as much as 1000 times (45-48). Some of the mechanisms are as follow: (1) antibiotic diffusion is limited via the matrix: for example, aminoglycosides penetrate via the matrix more slowly compard to $\beta$-lactams drugs; (2) resistance genes transmit across the community: Mobile genetic elements such as plasmids, transmits between cells by close contact, leading to spreading resistance markers; (3) the expression of efflux pumps is a drug resistance mechanism both in planktonic cells and in biofilm-producing bacteria; (4) antibiotics are inactivated by some changes in $\mathrm{pH}$ and metal ion concentrations. Each $\mathrm{pH}$ change in biofilms can inactivate antibiotics by the antibiotic activity anatomization; (5) metabolically, inactive cells denominate the persister cells. Persister cells are regular and dormant variants, which are not mutants. They act as a surviving cell reservoir for rebuilding the biofilm population (49). The acquisition of such a persisted status is mediated by toxin-antitoxin modules (50). The resistance level is associated with the biofilm formation stage. 


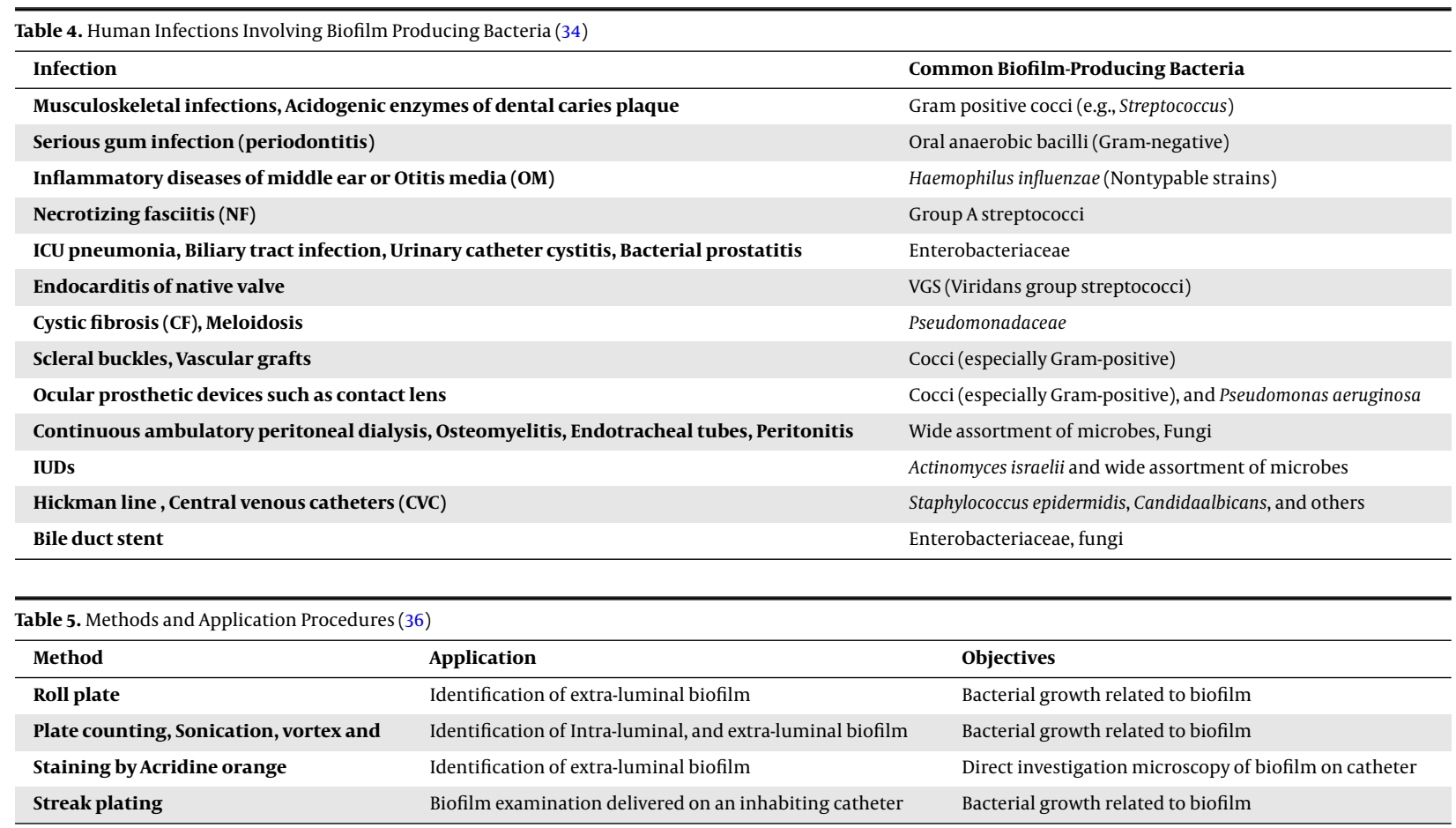

When bacteria have not connected themselves in the matrix, they become vulnerable against the actions of host immune system and antibiotics (51). In general, biofilm formation is accompanied by further resistance against host immune responses and antibiotics (52). The cells' characteristics in the matrix are protected from being exhibited to the innate immune system in antimicrobial therapy; hence, the communication of biochemical signals between them is facilitated (53). Moreover, it was demonstrated that the bacteria resistance in biofilm against the large number of antibiotics can be related to culture physiological conditions and density, not to their existence in the biofilm. On the other hand, the distribution of virulence factors and resistance characters can be enhanced by their construction (54). It was proved that biofilm formation raised the potentials of $S$. aureus against antibiotic resistance caused by plasmid by means of both mobile genetic elements, namely mobilization, and conjugation. This could be facilitated by close cell-to-cell contact in biofilms and may be prospered by the biofilm matrix (55).

\subsection{Diagnosis: Assays and Lab Devices of Biofilm Formation Evaluation}

In laboratories, microdilution and broth macrodilution methods are routinely used for detecting the antimicrobial activity of agents against planktonic microorganisms. The methods are introduced by NCCLS (National
Committee for Clinical Laboratory Standards), EUCAST(European Committee on Antimicrobial Susceptibility Testing), and CLSI (Clinical Laboratory Standards Institute). They, however, have never yield accurate results in biofilm producer microorganisms (2). There are several methods to detect microbial biofilm in response to agents (Tables 6 - 8). Moreover, several devices, including disk reactor, perfused biofilm fermenter, model bladder, centers for disease control (CDC) biofilm reactor, Calgary biofilm device, and modified Robbins device, have been improved as the model system. Providing information about biofilm mechanisms, these model systems define antimicrobial drugs susceptibility against biofilm-producing bacteria (36).

\subsection{Therapeutic Approaches}

Infection treatment associated with biofilm establishment requires further studies because of observing high levels of antibiotic resistance induced by biofilm structures. The concerned treatment is usually a mixed therapy, especially for infections induced by biofilm with macrolides such as clarithromycin, erythromycin, and azithromycin. These drugs display a wide range of antibiofilm activities against infections because of the biofilm occurred by gram-negative bacteria and prevent the production of alginate as a key matrix component (43).

It is documented that macrolides are effective against biofilms due to Staphylococcus spp. and P. aeruginosa 
Goudarzi M et al.

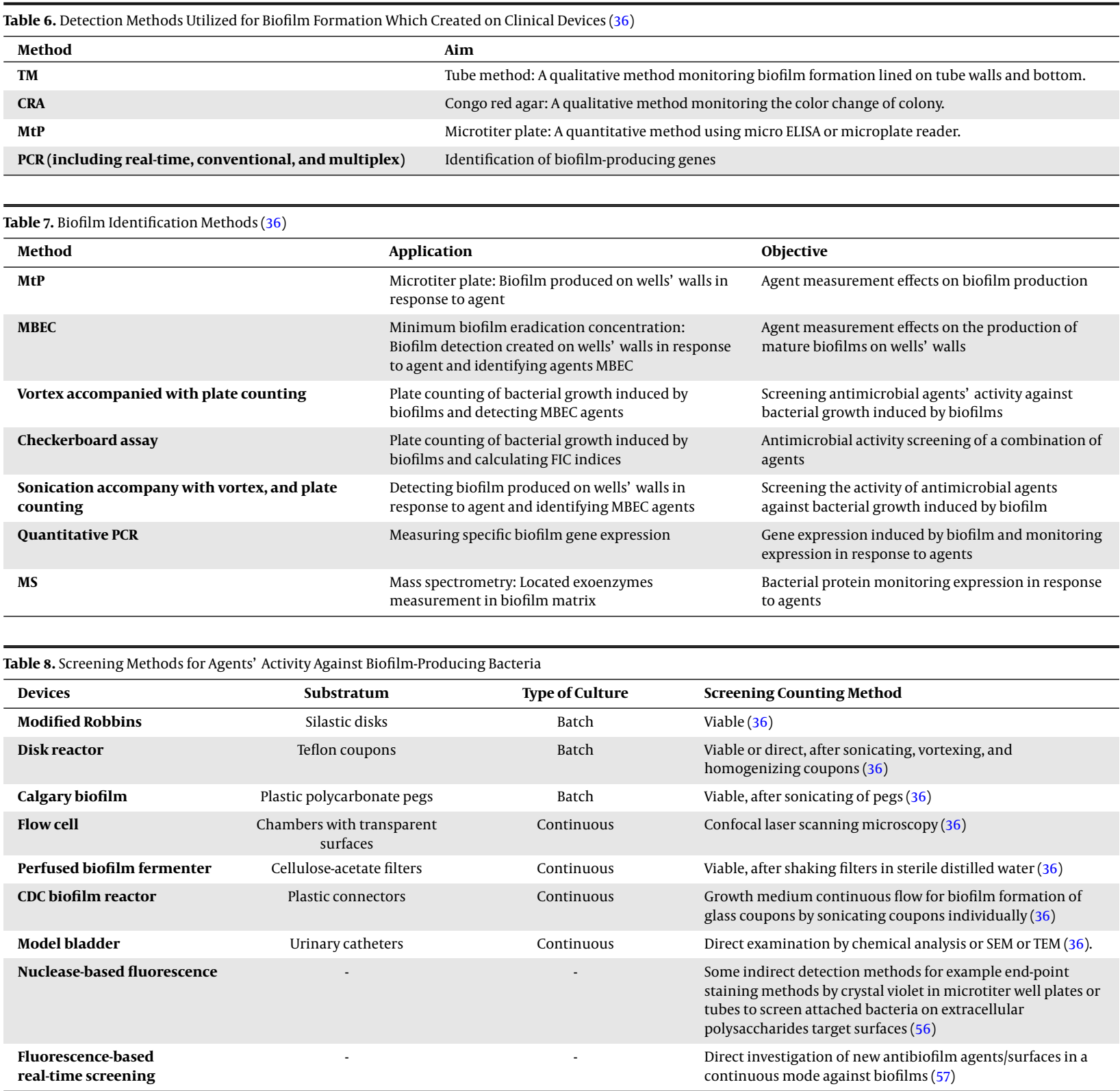

(58). Moreover; it is proved that the utilization of clarithromycin together with vancomycin is effective in eradicating both planktonic cells and biofilm structures (59). The usage of roxithromycin with imipenem facilitates the better neutrophils influx into biofilm backbone and unfixes the biofilm (60). The use of catheters to coat and impregnate these antimicrobial drugs is another approach to solve the problems with biofilm production (61). Further, due to its bactericidal actions, silver has also been used to coat catheters. Silver encompasses broad-spectrum antimicrobial characteristics $(62,63)$. The variants of the synthetic cationic peptide derived from natural peptides have been used as a strategy to target biofilms. Recently, some substances with antibacterial properties (e.g., genuine, nitrofurazone, and nitrous oxide) have been used to alter the urinary catheters' surface $(43,64)$.

Biofilm structure eradication is highly complicated due to the high levels of drug resistance presented by these constructions. Recent treatments are an alternative to medication with existing antibiotics to elude not only biofilm constitution but also resistant bacteria in underlying tissues. Table 9 presents a revision of some recent attitudes towards anti-biofilm treatments. 
Table 9. New Attitudes Towards Effective Biofilm Treatments

\begin{tabular}{l} 
Method \\
\hline Catheters covered with antibiotics or hydrogels \\
Antibiofilm treatments by nanoparticles
\end{tabular}

Iontophoresis Function

They are hydrophilic polymers making the catheter capable of increasing surface lubrication and consequently reducing the bacterial adhesion to this surface, thereby playing a role in decreasing the encrustation of catheters; An increase > 45\% in CAUTI is perceived by silver alloy employment in a urinary catheter covered by hydrogel $(65,66)$; It is proved that catheters covered with minocycline-rifampicin stop biofilm formation in Gram-negative and Gram-positive bacteria, Candida spp. and even P. aeruginosa (67)

These particles can stick and penetrate into bacterial cells, damage the bacterial membrane, and act with chromosomal DNA(68); Biofilm formation blockage in E. coli and S. aureus strains by glass surfaces coating with MgF nanoparticles is observed. Yttrium fluoride (YF3) nanoparticles have low solubility, extended protection, and low cytotoxicity (69); CaO-NPs (microwave irradiated CaO nanoparticles) have the potential to inhibit the biofilm production of Gram-negative and Gram-positive bacteria (70); Silver nanoparticles are applied for coating medical devices because of the silver antibacterial attributes. These nanoparticles, as part of biosensors, have been used in medical and pharmaceutical nano-engineering for diagnostic approaches, transfer, and therapeutic agents (71).

Iontophoresis, a physical process in a medium where ions stream diffusively, applies as an experimental, diagnostic, and therapeutic method. It uses voltage gradients as a kind of transdermal drug delivery procedure. It was proved that low electrical currents increase he tactivity of tobramycin and biocides against biofilm producing P. aeruginosa (72); Iontophoresis inhibit biofilm formation. Electric current use to these catheters covered by silver electrodes remarkably decreased their formation $(73,74)$.

Biofilm-degrading enzyme

A new antibiofilm urease induced by P. mirabilis convert change urea to ammonium ions; Fluorofamide can prohibit the enhancement in $\mathrm{pH}$ by Proteus mirabilis, thereby preventing the urea crystal formation and the subsequent encrustation and catheter blockage; Vanillic acid (75), natural plum juice, and germa- $\gamma$ - lactones (76) can forcefully prevent bacterial growth of crystal formation in catheters by inhibiting urease enzymes; $\mathrm{DspB}$, an enzyme pertaining to the bacteriophage and extracted from Actinobacillus species, ruin a crucial adhesion essential for biofilm production in E. coli and Staphylococcus (77); c-di-GMP is the second messenger significantly conserved among bacteria. It decreases biofilm production by reducing c-di-GMP inside cells (78).

Antagonism among different bacteria

Bacteriophages

Quorum sensing (QS) inhibitors

Antagonism can cause with using different E. coli avirulent strains $(79,80)$ such as E. coli, HU2117 strain originated from E. coli 83972. Avirulent strains can colonize persistently without any symptomatic infection (81); hence, it has been applied for urinary catheters to reduce of biofilm production by other pathogenic strains (80). In individuals with an intermittent catheterization, a decrease in the development of UTIs is reported.

Specifically, lytic phages (the natural predators of bacteria) can infect bacteria, interrupt the normal bacterial metabolism (especially the biofilms of P. mirabilis and E. coli), and support viral replication (82); Phages of $S$. aureus (83) with bactericidal activity control biofilm formation by replicating at infection site and depolymerize the destruction of the biofilm EPS matrix $(84,85)$.
QS is a kind of relationship among bacterial cells responding to extracellular signaling molecules, called autoinducers (AIs) (86). AIs, small signal molecules proportional to cell-density related to gene expression (87), can regulate several processes involved in virulence such as motility and biofilm formation (88). This is necessary for planktonic bacteria to present the biofilm phenotype. An effective QSI inhibitor should have some characteristics, as described below (89): A, capable of excluding gene expression pertaining to QS by a low molecular mass; B, significant specificity for QS regulators; C, No toxicity foreukaryotic cells, D, non-interference with the fundamental bacterial metabolic processes to elude the resistance development; $\mathrm{E}$, chemically permanent, resistant to the host metabolism, and inhabiting in the host cell for a long time; HSL, $\mathrm{N}$-acyl homoserine lactone, is analogous to the QS signal. It can emulates blocking QS, with signals to receptor binding, and prohibit the biofilm formation of S. aureus (90). Garlic extract can enhance the susceptibility against tobramycin by modifying the architecture of bacterial biofilms (91). Moreover, peptides display the QSI activity; The RNAIII-preventing peptide is capable of prohibiting agr-mediated biofilm production in drug resistant $S$. epidermidis $(90,92)$.

Low-energy surface acoustic waves (SAW) SAW intervenes with planktonic microorganisms' adhesion to cellular surfaces (88). It has been applied for urinary catheters to reduce of biofilm production by other pathogenic strains $(93,94)$.

It should specifically interact with the adhesions of pathogen and prohibit the union among pathogen and eukaryotic cell. It decreases invasion or host cells infection and eludes reversion; Cranberry produces a proanthocyanidin trimer in the extract and has an anti-adherence effect against uropathogenic E. coli (UPEC). Other antiadhesion agents are pilicides, mannosides, and curlicides (43).

\section{Conclusions}

About $80 \%$ of infectious diseases are induced by biofilms; hence, the ever-increasing proliferation of microbes against human-made medication and inherent capabilities such as biofilm production have expanded the challenges posed to medical sciences. In recent years, research efforts have focused on the progression of effective remedial techniques not generating drug resistance in mi- crobial association. In this regard, understanding bioavailability mechanisms, the survival and development of microbes within the biofilm structure, and the role of this feature in the spread of chronic diseases is a key to discovering effective methods to deal with germs. Despite extensive research on microbial biofilms, there are still some ambiguities regarding their mechanism of action, which highlights the significance of conducting further studies. 


\section{Acknowledgments}

We would like to express my gratitude to Dr. Mardani and Dr. Pourkaveh for providing us with a golden opportunity to conduct this wonderful project.

\section{Footnotes}

Authors' Contribution: It was not declared by the authors.

Conflict of Interests: The authors declare no conflict of interests.

Funding/Support: It was not declared by the authors.

\section{References}

1. Flemming HC, Wingender J. The biofilm matrix. Nat Rev Microbiol. 2010;8(9):623-33. doi: 10.1038/nrmicro2415. [PubMed: 20676145].

2. Kodali VP, Perali RS, Sen R. Purification and partial elucidation of the structure of an antioxidant carbohydrate biopolymer from the probiotic bacterium Bacillus coagulans RK-02.J Nat Prod. 2011;74(8):1692-7. doi: 10.1021/np1008448. [PubMed: 21800834].

3. Muhsin J, Ufaq T, Tahir H, Saadia A. Bacterial biofilm: its composition, formation and role in human infections.J Microbiol Biotechnol. 2015;4:1-14.

4. Lima J, Alves LR, Jacome P, Bezerra Neto JP, Maciel MAV, Morais MMC. Biofilm production by clinical isolates of Pseudomonas aeruginosa and structural changes in LasR protein of isolates non biofilm-producing. Braz J Infect Dis. 2018;22(2):129-36. doi: 10.1016/j.bjid.2018.03.003. [PubMed: 29601791].

5. Parker N, Schneegurt M, Tu AHT, Forster BM, Lister P. Microbiology. Texas, USA: OpenStax; 2017.

6. Yao Y, Sturdevant DE, Otto M. Genomewide analysis of gene expression in Staphylococcus epidermidis biofilms: Insights into the pathophysiology of S. epidermidis biofilms and the role of phenol-soluble modulins in formation of biofilms. J Infect Dis. 2005;191(2):289-98. doi: 10.1086/426945. [PubMed: 15609240].

7. Fux CA, Costerton JW, Stewart PS, Stoodley P. Survival strategies of infectious biofilms. Trends Microbiol. 2005;13(1):34-40. doi: 10.1016/j.tim.2004.11.010. [PubMed: 15639630].

8. Stoodley P, Kathju S, Hu FZ, Erdos G, Levenson JE, Mehta N, et al. Molecular and imaging techniques for bacterial biofilms in joint arthroplasty infections. Clin Orthop Relat Res. 2005;(437):31-40. doi: 10.1097/01.blo.0000175129.83084.d5. [PubMed: 16056023].

9. Muszanska AK, Nejadnik MR, Chen Y, van den Heuvel ER, Busscher $\mathrm{HJ}$, van der Mei HC, et al. Bacterial adhesion forces with substratum surfaces and the susceptibility of biofilms to antibiotics. Antimicrob Agents Chemother. 2012;56(9):4961-4. doi: 10.1128/AAC.00431-12. [PubMed: 22733073]. [PubMed Central: PMC3421903].

10. Rezaei M, Chavoshzadeh Z, Haroni N, Armin S, Navidinia M, Mansouri $\mathrm{M}$, et al. Colonization with methicillin resistant and methicillin sensitive Staphylococcus aureus subtypes in patients with atopic dermatitis and its relationship with severity of eczema. Arch Pediatr Infect Dis. 2013;1(2):53-6. doi: 10.5812/pedinfect.8969.

11. Navidinia M, Fallah F, Lajevardi B, Shirdoost M, Jamali J. Epidemiology of methicillin-resistant Staphylococcus aureus isolated from health care providers in Mofid Children Hospital. Arch Pediatr Infect Dis. 2015;3(2). e16458. doi: 10.5812/pedinfect.16458.

12. Navidinia M. The clinical importance of emerging ESKAPE pathogens in nosocomial infections. Journal of Paramedical Sciences. 2016;7(3):4357.
13. Navidinia M. Detection of inducible clindamycin resistance (MLSBi) among methicillin-resistant Staphylococcus aureus (MRSA) isolated from health care providers. Arch Adv Biosci. 2015;6(1).

14. Navidinia M, Goudarzi M, Rameshe SM, Farajollahi Z, Ebadi Asl P, Zaka Khosravi S, et al. Molecular characterization of resistance genes in MDR-ESKAPE pathogens. J Pure Appl Microbiol. 2017;11(2):779-92. doi: 10.22207/jpam.11.2.17.

15. Navidinia $M$, Armin S, Vosoghian S. Prevalence of blaOXA-1 and blaDHA-1 AmpC $\beta$-lactamase-producing and methicillin-resistant Staphylococcus aureus in Iran. Arch Pediatr Infect Dis. 2016;5(4). e36778. doi: 10.5812/pedinfect.36778.

16. Okada M, Sato I, Cho SJ, Iwata H, Nishio T, Dubnau D, et al. Structure of the Bacillus subtilis quorum-sensing peptide pheromone ComX. Nat Chem Biol. 2005;1(1):23-4. doi: 10.1038/nchembio709. [PubMed: 16407988].

17. Hentzer M, Eberl L, Givskov M. Transcriptome analysis of Pseudomonas aeruginosa biofilm development: Anaerobic respiration and iron limitation. Biofilms. 2005;2(1):37-61. doi: 10.1017/s1479050505001699.

18. Rivera LEC, Ramos AP, Desgarennes CP. Péptidos antimicrobianos: antibióticos naturales de la piel. Dermatología Revista Mexicana. 2007;51(2):57-67. Spanish.

19. Bassler BL, Miller MB. Quorum sensing. In: Falkow S, Rosenberg E, Schleifer KH, Stackebrandt E, editors. The prokaryotes: Ecophysiology and biochemistry. 2. New York, USA: Springer; 2006. p. 336-53. doi: 10.1007/0-387-30742-7_12.

20. Lopez MA, Nguyen HT, Oberholzer M, Hill KL. Social parasites. Curr Opin Microbiol. 2011;14(6):642-8. doi: 10.1016/j.mib.2011.09.012. [PubMed: 22020108]. [PubMed Central: PMC3230740].

21. Fanning S, Mitchell AP. Fungal biofilms. PLoS Pathog. 2012;8(4) e1002585. doi: 10.1371/journal.ppat.1002585. [PubMed: 22496639]. [PubMed Central: PMC3320593].

22. Poorabbas B, Mardaneh J, Rezaei Z, Kalani M, Pouladfar G, Alami MH, et al. Nosocomial Infections: Multicenter surveillance of antimicrobial resistance profile of Staphylococcus aureus and Gram negative rods isolated from blood and other sterile body fluids in Iran. Iran J Microbiol. 2015;7(3):127-35. [PubMed: 26668699]. [PubMed Central: PMC4676981].

23. Alsan M, Klompas M. Acinetobacter baumannii: An Emerging and Important Pathogen.J Clin Outcomes Manag. 2010;17(8):363-9. [PubMed: 26966345]. [PubMed Central: PMC4782967].

24. Pour NK, Dusane DH, Dhakephalkar PK, Zamin FR, Zinjarde SS, Chopade BA. Biofilm formation by Acinetobacter baumannii strains isolated from urinary tract infection and urinary catheters. FEMS Immunol Med Microbiol. 2011;62(3):328-38. doi: 10.1111/j.1574695X.2011.00818.x. [PubMed: 21569125].

25. Espinal P, Marti S, Vila J. Effect of biofilm formation on the survival of Acinetobacter baumannii on dry surfaces. J Hosp Infect. 2012;80(1):5660. doi: 10.1016/j.jhin.2011.08.013. [PubMed: 21975219].

26. Bahador A, Farshadzadeh Z, Raoofian R, Mokhtaran M, Pourakbari $\mathrm{B}$, Pourhajibagher $\mathrm{M}$, et al. Association of virulence gene expression with colistin-resistance in Acinetobacter baumannii: analysis of genotype, antimicrobial susceptibility, and biofilm formation. Ann Clin Microbiol Antimicrob. 2018;17(1):24. doi: 10.1186/s12941-018-0277-6. [PubMed: 29859115]. [PubMed Central: PMC5984448].

27. Nasirmoghadas P, Yadegari S, Moghim S, Esfahani BN, Fazeli H, Poursina F, et al. Evaluation of biofilm formation and frequency of multidrug-resistant and extended drug-resistant strain in Pseudomonas aeruginosa isolated from burn patients in Isfahan. Adv Biomed Res. 2018;7:61. doi: 10.4103/abr.abr_37_17. [PubMed: 29862210]. [PubMed Central: PMC5952530].

28. Shah $\mathrm{H}$, Bosch $\mathrm{W}$, Thompson KM, Hellinger WC. Intravascular catheter-related bloodstream infection. Neurohospitalist. 2013;3(3):144-51. doi: 10.1177/1941874413476043. [PubMed: 24167648]. [PubMed Central: PMC3805442]. 
29. Hoiby N, Bjarnsholt T, Moser C, Bassi GL, Coenye T, Donelli G, et al. ESCMID guideline for the diagnosis and treatment of biofilm infections 2014. Clin Microbiol Infect. 2015;21 Suppl 1:S1-25. doi: 10.1016/j.cmi.2014.10.024. [PubMed: 25596784].

30. Haussler S, Parsek MR. Biofilms 2009: New perspectives at the heart of surface-associated microbial communities. J Bacteriol. 2010;192(12):2941-9. doi: 10.1128/JB.00332-10. [PubMed: 20382760]. [PubMed Central: PMC2901683].

31. Naves P, del Prado G, Huelves L, Rodriguez-Cerrato V, Ruiz V, Ponte $\mathrm{MC}$, et al. Effects of human serum albumin, ibuprofen and N-acetylL-cysteine against biofilm formation by pathogenic Escherichia coli strains. J Hosp Infect. 2010;76(2):165-70. doi: 10.1016/j.jhin.2010.05.011. [PubMed: 20615578].

32. Percival SL, Kite P. Intravascular catheters and biofilm control. J Vasc Access. 2018;8(2):69-80. doi: 10.1177/112972980700800202.

33. Holmes CJ, Evans R. Biofilm and foreign body infection The significance to CAPD-associated peritonitis. Perit Dial Int. 1986;6(4):168-77.

34. Lewis K. Persister cells and the riddle of biofilm survival. Biochemistry (Mosc). 2005;70(2):267-74. doi: 10.1007/s10541-005-0111-6. [PubMed: 15807669].

35. Donlan RM. Biofilm formation: A clinically relevant microbiological process. Clin Infect Dis. 2001;33(8):1387-92. doi: 10.1086/322972. [PubMed: 11565080].

36. Kirmusaoglu S. Sensitizing of beta-lactam resistance by tannic acid in methicillin-resistant S. aureus. World J Microbiol Biotechnol. 2019;35(4):57. doi:10.1007/s11274-019-2637-6. [PubMed:30900046].

37. Donlan RM. Biofilms on central venous catheters: Is eradication possible? Curr Top Microbiol Immunol. 2008;322:133-61. doi: 10.1007/978-3540-75418-3_7. [PubMed:18453275].

38. Raad ,I, Mohamed JA, Reitzel RA, Jiang Y, Dvorak TL, Ghannoum MA, et al. The prevention of biofilm colonization by multidrugresistant pathogens that cause ventilator-associated pneumonia with antimicrobial-coated endotracheal tubes. Biomaterials. 2011;32(11):2689-94. doi: 10.1016/j.biomaterials.2010.12.015. [PubMed: 21295343].

39. Soto SM, Smithson A, Horcajada JP, Martinez JA, Mensa JP, Vila $\mathrm{J}$. Implication of biofilm formation in the persistence of urinary tract infection caused by uropathogenic Escherichia coli. Clin Microbiol Infect. 2006;12(10):1034-6. doi: 10.1111/j.1469-0691.2006.01543.x. [PubMed: 16961644].

40. Talsma SS. Biofilms on medical devices. Home Healthc Nurse. 2007;25(9):589-94. doi: 10.1097/01.NHH.0000296117.87061.14. [PubMed: 18049256].

41. Stickler DJ. Bacterial biofilms in patients with indwelling urinary catheters. Nat Clin Pract Urol. 2008;5(11):598-608. doi: 10.1038/ncpuro1231. [PubMed: 18852707].

42. Percival SL, Sabbuba NA, Kite P, Stickler DJ. The effect of EDTA instillations on the rate of development of encrustation and biofilms in Foley catheters. Urol Res. 2009;37(4):205-9. doi: 10.1007/s00240-0090196-2. [PubMed: 19468723].

43. Soto SM. Importance of biofilms in urinary tract infections: New therapeutic approaches. Advances in Biology. 2014;2014:1-13. doi: $10.1155 / 2014 / 543974$

44. Sanchez CJ, Mende K, Beckius ML, Akers KS, Romano DR, Wenke JC, et al. Biofilm formation by clinical isolates and the implications in chronic infections. BMC Infect Dis. 2013;13:47. doi: 10.1186/1471-2334-1347. [PubMed: 23356488]. [PubMed Central: PMC3568419].

45. Costerton JW, Montanaro L, Arciola CR. Bacterial communications in implant infections: A target for an intelligence war. Int J Artif Organs. 2007;30(9):757-63. doi: 10.1177/039139880703000903. [PubMed: 17918119].

46. Lewis K. Multidrug tolerance of biofilms and persister cells. Curr Top Microbiol Immunol. 2008;322:107-31. doi: 10.1007/978-3-540-75418-3_6. [PubMed: 18453274].

47. Soto SM. Role of efflux pumps in the antibiotic resistance of bacteria embedded in a biofilm. Virulence. 2013;4(3):223-9. doi: 10.4161/viru.23724. [PubMed: 23380871]. [PubMed Central: PMC3711980].

48. Van Acker H, Van Dijck P, Coenye T. Molecular mechanisms of antimicrobial tolerance and resistance in bacterial and fungal biofilms. Trends Microbiol. 2014;22(6):326-33. doi: 10.1016/j.tim.2014.02.001. [PubMed: 24598086].

49. Lafleur MD, Qi Q, Lewis K. Patients with long-term oral carriage harbor high-persister mutants of Candida albicans. Antimicrob Agents Chemother. 2010;54(1):39-44. doi: 10.1128/AAC.00860-09. [PubMed: 19841146]. [PubMed Central: PMC2798516].

50. Cerca N, Jefferson KK, Oliveira R, Pier GB, Azeredo J. Comparative antibody-mediated phagocytosis of Staphylococcus epidermidis cells grown in a biofilm or in the planktonic state. Infect Immun. 2006;74(8):4849-55. doi: 10.1128/IAI.00230-06. [PubMed: 16861673]. [PubMed Central: PMC1539625].

51. Cerca N, Oliveira R, Azeredo J. Susceptibility of Staphylococcus epidermidis planktonic cells and biofilms to the lytic action of staphylococcus bacteriophage K. Lett Appl Microbiol. 2007;45(3):313-7. doi: 10.1111/j.1472-765X.2007.02190.x. [PubMed:17718845].

52. Kirby AE, Garner K, Levin BR. The relative contributions of physical structure and cell density to the antibiotic susceptibility of bacteria in biofilms. Antimicrob Agents Chemother. 2012;56(6):296775. doi: 10.1128/AAC.06480-11. [PubMed: 22450987]. [PubMed Central: PMC3370779].

53. Savage VJ, Chopra I, O’Neill AJ. Staphylococcus aureus biofilms promote horizontal transfer of antibiotic resistance. Antimicrob Agents Chemother. 2013;57(4):1968-70. doi: 10.1128/AAC.02008-12. [PubMed: 23357771]. [PubMed Central: PMC3623343].

54. Parra-Ruiz J, Vidaillac C, Rybak MJ. Macrolides and staphylococcal biofilms. Rev Esp Quimioter. 2012;25(1):10-6. [PubMed: 22488536].

55. Fujimura S, Sato T, Kikuchi T, Zaini J, Gomi K, Watanabe A. Efficacy of clarithromycin plus vancomycin in mice with implant-related infection caused by biofilm-forming Staphylococcus aureus. J Orthop Sci. 2009;14(5):658-61. doi: 10.1007/s00776-009-1366-3. [PubMed: 19802681].

56. Mozioğlu E, Kocagöz T. Synthetic DNA molecules in biosensing of biofilms. Int J Environ Anal Chem. 2019;100(4):378-82. doi: 10.1080/03067319.2019.1682141.

57. Mozioğlu E. Fluorescence-based real-time monitoring of Pseudomonas aeruginosa and a simple, continuous screening method for detection of antibiofilm activity. Int $J$ Environ Anal Chem. 2019;100(4):383-92. doi:10.1080/03067319.2019.1685091.

58. Wang Q, Sun FJ, Liu Y, Xiong LR, Xie LL, Xia PY. Enhancement of biofilm formation by subinhibitory concentrations of macrolides in icaADBC-positive and -negative clinical isolates of Staphylococcus epidermidis. Antimicrob Agents Chemother. 2010;54(6):2707-11. doi: 10.1128/AAC.01565-09. [PubMed: 20231401]. [PubMed Central: PMC2876384].

59. Hamill TM, Gilmore BF, Jones DS, Gorman SP. Strategies for the development of the urinary catheter. Expert Rev Med Devices. 2007;4(2):21525. doi: 10.1586/17434440.4.2.215. [PubMed: 17359226].

60. Regev-Shoshani G, Ko M, Crowe A, Av-Gay Y. Comparative efficacy of commercially available and emerging antimicrobial urinary catheters against bacteriuria caused by E. coli in vitro. Urology. 2011;78(2):334-9. doi: 10.1016/j.urology.2011.02.063. [PubMed: 21820571].

61. Siddiq DM, Darouiche RO. New strategies to prevent catheterassociated urinary tract infections. Nat Rev Urol. 2012;9(6):305-14. doi: 10.1038/nrurol.2012.68. [PubMed: 22508462].

62. Kazmierska KA, Thompson R, Morris N, Long A, Ciach T. In vitro multicompartmental bladder model for assessing blockage of urinary catheters: effect of hydrogel coating on dynamics of Proteus mirabilis growth. Urology. 2010;76(2):515 e15-20. doi: 10.1016/j.urology.2010.04.039. [PubMed: 20696356].

63. Rupp ME, Fitzgerald T, Marion N, Helget V, Puumala S, Anderson JR, et 
al. Effect of silver-coated urinary catheters: efficacy, cost-effectiveness, and antimicrobial resistance. Am J Infect Control. 2004;32(8):445-50. doi:10.1016/j.ajic.2004.05.002. [PubMed: 15573050].

64. Davenport K, Keeley FX. Evidence for the use of silver-alloycoated urethral catheters. J Hosp Infect. 2005;60(4):298-303. doi: 10.1016/j.jhin.2005.01.026. [PubMed:15936115].

65. Lellouche J, Kahana E, Elias S, Gedanken A, Banin E. Antibiofilm activity of nanosized magnesium fluoride. Biomaterials. 2009;30(30):5969-78. doi: 10.1016/j.biomaterials.2009.07.037. [PubMed: 19664818].

66. Lellouche J, Friedman A, Gedanken A, Banin E. Antibacterial and antibiofilm properties of yttrium fluoride nanoparticles. Int $J$ Nanomedicine. 2012;7:5611-24. doi: 10.2147/IJN.S37075. [PubMed: 23152681]. [PubMed Central: PMC3496407].

67. Roy A, Gauri SS, Bhattacharya M, Bhattacharya J. Antimicrobial activity of caO nanoparticles. J Biomed Nanotechnol. 2013;9(9):1570-8. doi: 10.1166/jbn.2013.1681. [PubMed: 23980504].

68. Fey PD. Modality of bacterial growth presents unique targets: How do we treat biofilm-mediated infections? Curr Opin Microbiol. 2010;13(5):610-5. doi:10.1016/j.mib.2010.09.007. [PubMed: 20884280]. [PubMed Central: PMC2966470].

69. Markowska K, Grudniak AM, Wolska KI. Silver nanoparticles as an alternative strategy against bacterial biofilms. Acta Biochim Pol. 2013;60(4):523-30. [PubMed: 24432308].

70. Lu TK, Collins JJ. Dispersing biofilms with engineered enzymatic bacteriophage. Proc Natl Acad Sci USA. 2007;104(27):11197-202. doi: 10.1073/pnas.0704624104. [PubMed: 17592147]. [PubMed Central: PMC1899193].

71. Chakravarti A, Gangodawila S, Long MJ, Morris NS, Blacklock AR, Stickler DJ. An electrified catheter to resist encrustation by Proteus mirabilis biofilm. J Urol. 2005;174(3):1129-32. doi: 10.1097/01.ju.0000168618.79096.cb. [PubMed:16094079].

72. Morris NS, Stickler DJ. Encrustation of indwelling urethral catheters by Proteus mirabilis biofilms growing in human urine. J Hosp Infect. 1998;39(3):227-34. doi: 10.1016/s0195-6701(98)90262-6. [PubMed: 9699143].

73. Torzewska A, Rozalski A. Inhibition of crystallization caused by Proteus mirabilis during the development of infectious urolithiasis by various phenolic substances. Microbiol Res. 2014;169(7-8):579-84. doi: 10.1016/j.micres.2013.09.020. [PubMed: 24239192].

74. Ghanwate NA, Tiwari AA, Thakare PV. Importance of biofilm in medical sciences: With special reference to uropathogens. Afr J Microbiol Res. 2016;10(34):1371-9. doi: 10.5897/ajmr2016.8178.

75. Raad I, Mohamed JA, Reitzel RA, Jiang Y, Raad S, Al Shuaibi M, et al. Improved antibiotic-impregnated catheters with extended-spectrum activity against resistant bacteria and fungi. Antimicrob Agents Chemother. 2012;56(2):935-41. doi: 10.1128/AAC.05836-11. [PubMed: 22123686]. [PubMed Central: PMC3264266].

76. Itoh Y, Wang X, Hinnebusch BJ, Preston J3, Romeo T. Depolymerization of beta-1,6-N-acetyl-D-glucosamine disrupts the integrity of diverse bacterial biofilms. J Bacteriol. 2005;187(1):382-7. doi: 10.1128/JB.187.1.382-387.2005. [PubMed: 15601723]. [PubMed Central: PMC538831].

77. Trautner BW, Hull RA, Darouiche RO. Escherichia coli 83972 inhibits catheter adherence by a broad spectrum of uropathogens. Urology. 2003;61(5):1059-62. doi: 10.1016/s0090-4295(02)02555-4. [PubMed: 12736047]. [PubMed Central: PMC2963591].

78. Sambanthamoorthy K, Luo C, Pattabiraman N, Feng X, Koestler $\mathrm{B}$, Waters $\mathrm{CM}$, et al. Identification of small molecules inhibiting diguanylate cyclases to control bacterial biofilm development. Biofouling. 2014;30(1):17-28. doi: 10.1080/08927014.2013.832224. [PubMed: 24117391]. [PubMed Central: PMC4120261].

79. Prasad A, Cevallos ME, Riosa S, Darouiche RO, Trautner BW. A bacterial interference strategy for prevention of UTI in persons practicing intermittent catheterization. Spinal Cord. 2009;47(7):565-
9. doi: 10.1038/sc.2008.166. [PubMed: 19139758]. [PubMed Central: PMC2705471].

80. Darouiche RO, Thornby JI, Cerra-Stewart C, Donovan WH, Hull RA. Bacterial interference for prevention of urinary tract infection: A prospective, randomized, placebo-controlled, double-blind pilot trial. Clin Infect Dis. 2005;41(10):1531-4. doi: 10.1086/497272. [PubMed: 16231269].

81. Carson L, Gorman SP, Gilmore BF. The use of lytic bacteriophages in the prevention and eradication of biofilms of Proteus mirabilis and Escherichia coli. FEMS Immunol Med Microbiol. 2010;59(3):447-55. doi: 10.1111/j.1574-695X.2010.00696.x. [PubMed: 20528927].

82. Curtin JJ, Donlan RM. Using bacteriophages to reduce formation of catheter-associated biofilms by Staphylococcus epidermidis. Antimicrob Agents Chemother. 2006;50(4):1268-75. doi: 10.1128/AAC.50.4.12681275.2006. [PubMed: 16569839]. [PubMed Central: PMC1426991].

83. Fu W, Forster T, Mayer O, Curtin JJ, Lehman SM, Donlan RM. Bacteriophage cocktail for the prevention of biofilm formation by Pseudomonas aeruginosa on catheters in an in vitro model system. Antimicrob Agents Chemother. 2010;54(1):397-404. doi:10.1128/AAC.00669-09. [PubMed: 19822702]. [PubMed Central: PMC2798481].

84. Novick RP, Geisinger E. Quorum sensing in staphylococci. Annu Rev Genet. 2008;42:541-64. doi: 10.1146/annurev.genet.42.110807.091640. [PubMed: 18713030].

85. Zhu H, Sun X, Lu J, Wang M, Fang Y, Ge W. The effect of plum juice on the prevention of struvite calculus formation in vitro. BJU Int. 2012;110(8 Pt B):E362-7. doi: 10.1111/j.1464-410X.2012.11090.x. [PubMed: 22900675].

86. Rasmussen TB, Givskov M. Quorum-sensing inhibitors as antipathogenic drugs. Int $J$ Med Microbiol. 2006;296(2-3):149-61. doi: 10.1016/j.ijmm.2006.02.005. [PubMed:16503194].

87. Hentzer M, Givskov M. Pharmacological inhibition of quorum sensing for the treatment of chronic bacterial infections. J Clin Invest. 2003;112(9):1300-7. doi: 10.1172/JCI20074. [PubMed: 14597754]. [PubMed Central: PMC228474].

88. Hentzer M, Eberl L, Nielsen J, Givskov M. Quorum sensing: A novel target for the treatment of biofilm infections. BioDrugs. 2003;17(4):24150. doi: 10.2165/00063030-200317040-00003. [PubMed: 12899641].

89. Hentzer M, Wu H, Andersen JB, Riedel K, Rasmussen TB, Bagge N, et al. Attenuation of Pseudomonas aeruginosa virulence by quorum sensing inhibitors. EMBO J. 2003;22(15):3803-15. doi: 10.1093/emboj/cdg366. [PubMed:12881415]. [PubMed Central: PMC169039].

90. Balaban N, Giacometti A, Cirioni O, Gov Y, Ghiselli R, Mocchegiani F, et al. Use of the quorum-sensing inhibitor RNAIII-inhibiting peptide to prevent biofilm formation in vivo by drug-resistant Staphylococcus epidermidis. J Infect Dis. 2003;187(4):625-30. doi: 10.1086/345879. [PubMed: 12599079].

91. Rediske AM, Roeder BL, Nelson JL, Robison RL, Schaalje GB, Robison RA, et al. Pulsed ultrasound enhances the killing of Escherichia coli biofilms by aminoglycoside antibiotics in vivo. Antimicrob Agents Chemother. 2000;44(3):771-2. doi: 10.1128/AAC.44.3.771772.2000. [PubMed: 10681355]. [PubMed Central: PMC89763].

92. Hazan Z, Zumeris J, Jacob H, Raskin H, Kratysh G, Vishnia M, et al. Effective prevention of microbial biofilm formation on medical devices by low-energy surface acoustic waves. Antimicrob Agents Chemother. 2006;50(12):4144-52. doi: 10.1128/AAC.00418-06. [PubMed: 16940055]. [PubMed Central: PMC1693972].

93. Hensel Z, Xiao J. A mechanism for stochastic decision making by bacteria. Chembiochem. 2009;10(6):974-6. doi: 10.1002/cbic.200800824. [PubMed: 19294726].

94. Lohr G, Beikler T, Podbielski A, Standar K, Redanz S, Hensel A. Polyphenols from Myrothamnus flabellifolia Welw. inhibit in vitro adhesion of Porphyromonas gingivalis and exert anti-inflammatory cytoprotective effects in KB cells. J Clin Periodontol. 2011;38(5):457-69. doi: 10.1111/j.1600-051X.2010.01654.x. [PubMed: 21158896]. 